\title{
A Inteligência Competitiva na Perspectiva de ser uma Fonte de Vantagem Competitiva e suas Contribuições ESTRATÉGICAS
}

\author{
Competitive Intelligence in Perspective to be a Source of \\ Competitive Advantage and Strategic Contributions
}

Felipe Gama Buzzerio

Supervisor de Inteligência de Mercado das Organizações Globo. São Paulo, SP. Brasil. E-mail: felipegamabuzz@yahoo.com.br

Reynaldo Cavalheiro Marcondes

Professor Titular do Programa de Pós-Graduação em Administração de Empresas da Universidade Presbiteriana Mackenzie. São

Paulo, SP. Brasil. E-mail: reynaldo.marcondes@mackenzie.br

\section{Resumo}

Este artigo examina a perspectiva de a Inteligência Competitiva (IC) se constituir em uma fonte de vantagem competitiva, à luz da Visão Baseada em Recursos, e sua contribuição para a administração estratégica da empresa. Apoia-se em pesquisa exploratória e descritiva com a utilização do método qualitativo. Foram entrevistados seis gestores responsáveis pelas atividades de IC institucionalizadas em empresas de grande porte de negócios diferentes. Os dados foram tratados e analisados com a aplicação da Análise de Conteúdo. Concluiu-se que a IC não pode ser considerada como uma fonte de vantagem competitiva, mas sim como um apoio efetivo ao processo decisório nas empresas da pesquisa. Aparentemente, os produtos da IC atendem às necessidades pontuais dos clientes internos, facilitam a integração da IC com marketing e operações e ajudam na identificação de riscos por meio da análise das informações de natureza estratégica, o que constitui um diferenciador da IC em relação às outras inteligências.

Palavras-chave: Administração Estratégica. Visão Baseada em Recursos. Inteligência Competitiva. Recursos Estratégicos. Vantagem Competitiva.

\section{Abstract}

This article examines the prospect of Competitive Intelligence $(\mathrm{CI})$ constitute a source of competitive advantage in light of the Resource Based View and its contribution to the strategic management of the company. Relies on exploratory and descriptive research using the qualitative method. Six managers responsible for $\mathrm{CI}$ activities institutionalized in large different business companies were interviewed. Data were processed and analyzed with the application of content analysis. It was concluded that the $\mathrm{CI}$ is unable to be a source of competitive advantage but rather as an effective support to decision making process in the surveyed companies. Apparently CI products meet the specific needs of internal customers, facilitate the integration of $\mathrm{CI}$ with marketing and operations, help in the identification of risks through the analysis of strategic information, which is a differentiator compared to other types of intelligences.

Keywords: Strategic Management. Resource Based View. Competitive Intelligence. Strategic Resources. Competitive Advantage. 


\section{INTRODUÇÃO}

A Inteligência Competitiva (IC), de maneira geral, tem sido tratada na literatura dentro da administração estratégica, mas de maneira pouco expressiva, como um dos instrumentos relevantes na identificação de oportunidades e ameaças para a tomada de decisões na organização, por vezes, sobreposta em relação a outros instrumentos de inteligência. Por outro lado, essa atividade tem visto aumentar a sua utilização nas organizações.

Para Oliveira, Gonçalves e Paula (2013), a IC tem se tornado um importante campo de pesquisas na atualidade e muitas questões ainda precisam ser exploradas especialmente no contexto das organizações brasileiras.

Entende-se por Inteligência Competitiva (IC) as atividades de suporte à direção da organização com o objetivo de interpretar as informações a respeito de elementos do seu ambiente externo, de maneira a antecipar oportunidades e ameaças, por intermédio de processos analíticos. (RODRIGUES; RICCARDI, 2007; FLEISHER; BENSOUSSAN, 2007; SHARP, 2009)

Segundo Dishman e Calof (2008), na prática, o processo de IC se estrutura de maneira a manter sempre seu alinhamento com as necessidades estratégicas da organização, com um foco expressivo na coleta das informações necessárias para realizar as análises.

Outra maneira de ver a IC na organização é como facilitadora do processo de formulação da estratégia (TYSON, 1998). Isso implica em não somente prover os decisores com análises elaboradas com mais profundidade, mas também com ideias e orientações para a melhor construção de estratégias.

Segundo Prescott (1999), a origem da IC está nas atividades de inteligência militar. Após a Segunda Guerra Mundial desenvolveu-se nos EUA uma significativa atividade de inteligência com o intuito de apoiar a segurança nacional. Contudo, foi no início da década de 1980 (PORTER, 1986; PRESCOTT, 1999) que a IC começou a ganhar evidência no âmbito dos negócios empresariais, embora alguns dos seus conceitos sejam anteriores a essa data. (CALOF; WRIGHT, 2008)

Atualmente, há diversas iniciativas, em âmbito internacional, voltadas à sua adoção e ao seu desenvolvimento, com relação às organizações. A Academy of Competitive Intelligence, uma instituição norte-ame- ricana de treinamento em IC (ACADEMY, 2010), tem realizado treinamentos para funcionários de empresas do porte de ALCOA, American Express, AT\&T, Boeing, Caterpillar, Coca-Cola, DuPont Pharmaceuticals, Ford, Hewlett-Packard, IBM, Motorola, Petrobras, Reebok, SAP America e Shell. Além dela, a consultoria Global Intelligence Alliance disponibiliza, em seu site, diversos casos de organizações que utilizam a IC com diferentes objetivos, seja para definir argumentos de venda na Tetra Pak, acompanhar aspectos técnicos dos produtos concorrentes na Pirelli ou estudar cenários futuros na Shell (GLOBAL, 2010), evidenciando uma diversidade de negócios na sua utilização.

Diante disso, algumas perguntas se tornam instigantes, tendo em vista as lacunas na literatura, quais sejam, a IC pode se constituir em uma fonte de vantagem competitiva? Como se posiciona esta atividade na organização que a adota? Com que fundamentos ela seria considerada como estratégica?

Os conceitos, as visões e as práticas, já apresentados, mostram que a IC é um meio de se buscar a conexão entre os ambientes interno e o externo das organizações. Nesse sentido, entre as diversas maneiras de tratar do assunto, a Visão Baseada em Recursos (VBR) foi a abordagem adotada na pesquisa que suporta este artigo, por ser esta suficientemente consolidada como fundamentação teórica da área de estudos da administração estratégica. (NOTHNAGEL, 2008)

Harrison (2005), Johnson, Scholes e Whittington (2007) e Barney (2011) entendem que as organizações analisam seu ambiente externo para estabelecer as suas estratégias. De acordo com a VBR, a vantagem competitiva sustentável tem as suas fontes nos recursos internos que devem ser heterogêneos e difíceis de serem transferidos, em relação aos concorrentes. (BARNEY, 1991)

Makadok e Barney (2001) entendem que a administração eficiente de recursos passa, entre outros aspectos, pela análise do ambiente externo da organização e que sempre há uma lacuna de informação na fase de análise da situação (HARRISON, 2005; MAKADOK; BARNEY, 2001; RAJANIEMI, 2007). Como há sempre decisões a serem tomadas sobre investimentos, Choo (2003) defende que é necessário o conhecimento resultante do processo analítico para fazer as escolhas das opções que se apresentem. 
Para Bollinger e Smith (2001), a abordagem do produto da IC, por meio dos conceitos do conhecimento, é importante pelo fato desse último poder ser uma fonte de vantagem competitiva.

Com base nas considerações feitas nesta introdução, definiu-se como objetivo deste artigo, examinar a perspectiva da IC se constituir em uma fonte de vantagem competitiva, com base na caracterização da sua inserção na administração estratégica da organização e na identificação dos atributos a ela inerentes, como um possível recurso estratégico.

Nas seções seguintes será apresentada a fundamentação teórica, que explora conceitos sobre a VBR e a IC; na sequência, serão abordados os procedimentos metodológicos com as justificativas da natureza exploratória da pesquisa, a opção pelo método qualitativo e a aplicação da análise de conteúdo, que orientaram a coleta e tratamento dos dados, seguidos da análise dos resultados obtidos nas entrevistas, concluindo com as considerações finais a respeito do que foi aprendido com a pesquisa.

\section{Referencial Teórico}

Esta seção apresentará a fundamentação dos conceitos relacionados com o objetivo do artigo.

\subsection{Administração Estratégica das Organizações}

A administração estratégica de uma organização, de acordo com a VBR, envolve entender a posição em que uma organização se encontra em relação a fatores internos e externos para tomar decisões a respeito do seu futuro (JOHNSON; SCHOLES; WHITTINGTON, 2007). A posição estratégica, de acordo com Barney (2011), exige se compreender as oportunidades e ameaças existentes no ambiente externo diante das forças e fraquezas da organização.

Hitt, Ireland e Hoskisson (2008) entendem que a administração estratégica é um conjunto de ações e de compromissos pensados com o intuito de obter vantagem competitiva e retornos acima da média, de maneira semelhante ao entendimento de Barney e Clark (2007) que defendem ser a administração estratégica uma sequência de análises e de escolhas que objetivam levar a organização à condição de vantagem competitiva.

A atividade chamada de análise da situação, integrante do processo da administração estratégica (HARRISON, 2005), foca tanto o ambiente externo como o ambiente interno. Em outras palavras, em um momento há o olhar para dentro da organização e, em outro, o olhar para fora dela. O ambiente externo é relevante por conter incertezas derivadas da interpretação feita das oportunidades e ameaças, e suas mudanças tem impacto direto na eficiência das ações empreendidas pela organização, ao mesmo tempo em que são fontes de informações para alimentar as decisões estratégicas. (HITT; IRELAND; HOSKISSON, 2008)

Como o ambiente geral é composto por variáveis amplas e inter-relacionadas, o entendimento de cada uma dessas variáveis, suas características, inter-relações, importância e impacto para a organização é crucial para se extrair oportunidades e ameaças. (BARNEY; CLARK, 2007)

Para Porter (1986), com quem autores da VBR fazem contraponto, o ambiente externo é aquele do setor econômico e que sujeita a organização à influência de cinco forças que podem ameaçar os seus resultados, por meio do poder de negociação dos fornecedores, dos novos entrantes no setor, dos serviços ou produtos substitutos, do poder de negociação dos consumidores e clientes, que definem a força da rivalidade entre as empresas. Pelo fato de essa abordagem ser a atratividade do setor, resultante da atuação dessas forças, a organização é levada a adotar estratégias para obtenção da vantagem competitiva. Esse é o ponto focal da diferença com os autores da VBR que defendem serem os recursos e capacidades as fontes de vantagem competitiva (BARNEY, 2011), apesar de eles também utilizarem o constructo das cinco forças atuantes no ambiente externo e levarem em conta o ambiente externo.

No processo de administração estratégica, a etapa de análise da situação (especialmente a parte do ambiente externo) é caracterizada pelo esforço de obter-se conhecimento para definição de opções estratégicas e escolhas. Porém, quando se trata de uma questão de tomar decisões, parte-se do princípio de que estas só podem ser tomadas mediante apropriação do conhecimento. (CHOO, 2003) 
Para Makadok e Barney (2001), a geração do conhecimento é que deixa espaço para a IC poder ser inserida no processo de administração estratégica, como geradora de conhecimento a respeito do ambiente externo.

\subsection{Conceituando a Inteligência Competitiva (IC)}

Adotou-se neste artigo o nome Inteligência Competitiva, defendido por Sharp (2009), por mostrar com mais clareza a diferença em relação a outras "inteligências", como business intelligence, inteligência estratégica, competitor analysis, competitive technical intelligence e inteligência de mercado (DISHMAN; CALOF, 2008). Apesar de não haver unanimidade entre os autores sobre os conceitos de cada uma delas, conforme Abreu (2006) e Rodrigues e Riccardi (2007), alguns autores diferenciam a IC das demais inteligências, sem exclui-la totalmente.

Sharp (2009) faz uma menção às diferenças ente a IC e pesquisa de mercado, business intelligence, inteligência de mercado, open source intelligence $e$ gestão do conhecimento. Seu principal argumento é que, embora esses conceitos sejam similares à IC, nem todos os aspectos são comuns. Por exemplo, embora a IC produza conhecimento estratégico, ela não tem o mesmo objetivo, como mecanismo, da gestão do conhecimento. Outros autores, como Calof e Wright (2008), ampliam o foco da IC para além dos competidores, como ocorre com o conceito de competitor analysis. Em resumo, para Dishman e Calof (2008) a IC não pode se confundir com nenhum desses conceitos mencionados, e vice-versa, principalmente por conta de seu processo analítico de informações.

O Quadro 1 sumariza a diferenciação feita por Sharp (2009) entre a IC e as demais atividades que costumam ser confundidas com ela.

A IC desperta diversas concepções como atividade na organização, tanto do ponto de vista de processo, quanto do ponto de vista de seu posicionamento na estrutura organizacional. De qualquer maneira, uma definição geral e ampla é a da IC como uma atividade de captura, interpretação e comunicação interna de informações de maneira a auxiliar as pessoas da organização a compreenderem melhor as forças do ambiente externo que devem ser consideradas em suas decisões, antecipando eventos relevantes. (RODRIGUES; RICCARDI, 2007; DISHMAN; CALOF, 2008; CALOF; WRIGHT, 2008; SHARP, 2009)

\begin{tabular}{|c|c|}
\hline $\begin{array}{l}\text { ATIVIDADES DE } \\
\text { INTELIGÊNCIA }\end{array}$ & Foco \\
\hline $\begin{array}{l}\text { Business } \\
\text { Intelligence }\end{array}$ & $\begin{array}{l}\text { Esse termo se refere principalmente à atividade } \\
\text { de coletar e estruturar grandes quantidades } \\
\text { de dados. Geralmente é utilizado no âmbito } \\
\text { de tecnologia da informação. }\end{array}$ \\
\hline $\begin{array}{l}\text { Inteligência } \\
\text { de Mercado }\end{array}$ & $\begin{array}{l}\text { Tomado frequentemente como sinônimo de } \\
\text { IC, se refere mais à prática de analisar a } \\
\text { variável "mercado" do ambiente externo, } \\
\text { como IC pode ser aplicada a tecnologia, } \\
\text { consumidores, fornecedores, entre outros. }\end{array}$ \\
\hline $\begin{array}{l}\text { Open Source } \\
\text { Intelligence }\end{array}$ & $\begin{array}{l}\text { Termo utilizado no âmbito militar, migrado } \\
\text { recentemente para o âmbito das organizações, } \\
\text { se refere à prática de inteligência que utiliza } \\
\text { apenas fontes abertas de informação. }\end{array}$ \\
\hline $\begin{array}{l}\text { Pesquisa de } \\
\text { Mercado }\end{array}$ & $\begin{array}{l}\text { Apesar de similares, o processo e os resultados } \\
\text { da pesquisa de mercado e da IC são diferentes } \\
\text { quanto ao seu escopo: enquanto a pesquisa } \\
\text { de mercado se preocupa em explicar eventos } \\
\text { passados, a IC busca identificar possíveis } \\
\text { eventos futuros. }\end{array}$ \\
\hline $\begin{array}{l}\text { Gestão do } \\
\text { Conhecimento }\end{array}$ & $\begin{array}{l}\text { A maneira como a IC e a gestão do } \\
\text { conhecimento coletam informações } \\
\text { disponíveis dentro da organização é similar. } \\
\text { No entanto, a IC tem um foco maior em obter } \\
\text { informações de fora da organização, além de } \\
\text { fazer um uso diferente da informação. Em } \\
\text { outras palavras, a IC analisa a informação e } \\
\text { distribui o conhecimento resultante, enquanto } \\
\text { a gestão do conhecimento se preocupa com } \\
\text { a coleta e disseminação de um determinado } \\
\text { conhecimento. }\end{array}$ \\
\hline
\end{tabular}

Quadro 1: A IC em relação às demais inteligências

Fonte: Elaborado pelos autores com base em Sharp (2009)

Com relação à evolução da IC, Prescott (1999) mostrou como ela se tornou cada vez mais integrada ao processo decisório na organização, conforme ilustra o Quadro 2. 


\begin{tabular}{|l|l|l|l|l|}
\hline \multicolumn{1}{|c|}{ PERíodo DE TEMPO } & \multicolumn{1}{|c|}{ ANTERIOR A $\mathbf{1 9 8 0}$} & \multicolumn{1}{|c|}{$\mathbf{1 9 8 0}$ A $\mathbf{1 9 8 7}$} & \multicolumn{1}{c|}{$\mathbf{1 9 8 8}$ A $\mathbf{1 9 9 9}$} & \multicolumn{1}{c|}{ FutuRo } \\
\hline $\begin{array}{l}\text { Estágios de } \\
\text { desenvolvimento }\end{array}$ & $\begin{array}{l}\text { Coleta de dados } \\
\text { competitivos }\end{array}$ & $\begin{array}{l}\text { Análise da indústria } \\
\text { e dos concorrentes }\end{array}$ & Inteligência Competitiva & $\begin{array}{l}\text { Inteligência Competitiva } \\
\text { como core capability }\end{array}$ \\
\hline $\begin{array}{l}\text { Grau de } \\
\text { formalização da IC }\end{array}$ & Informal & $\begin{array}{l}\text { Surgimento de } \\
\text { funções formais }\end{array}$ & Função formal & $\begin{array}{l}\text { Combinação entre } \\
\text { formal } \text { informal }\end{array}$ \\
\hline $\begin{array}{l}\text { Tipo de análise } \\
\text { realizada }\end{array}$ & Pouca ou nenhuma & Apenas quantitativa & $\begin{array}{l}\text { Combinação entre } \\
\text { quantitativa e qualitativa }\end{array}$ & $\begin{array}{l}\text { Predominantemente } \\
\text { qualitativa }\end{array}$ \\
\hline $\begin{array}{l}\text { Ligação com o } \\
\text { processo decisório }\end{array}$ & Pouca & Fraca & Forte & Input direto \\
\hline $\begin{array}{l}\text { Posição na } \\
\text { estrutura } \\
\text { organizacional }\end{array}$ & Biblioteca/marketing & $\begin{array}{l}\text { Planejamento/ } \\
\text { marketing }\end{array}$ & $\begin{array}{l}\text { Marketing/ planejamento/ } \\
\text { unidade de IC }\end{array}$ & $\begin{array}{l}\text { Unidades de IC/ } \\
\text { marketing/ planejamento }\end{array}$ \\
\hline
\end{tabular}

Quadro 2: Evolução da Inteligência Competitiva

Fonte: Adaptado de Prescott (1999)

No que se refere às informações que a IC captura do ambiente externo, pela concepção de Sharp (2009), diversos elementos do ambiente externo são envolvidos, não necessariamente de maneira simultânea, mas sim de maneira a suprir as necessidades de informação da organização (RODRIGUES; RICCARDI, 2007). Com isso, a IC é passível de ter seu foco direcionado para diferentes elementos do ambiente externo (CALOF; WRIGHT, 2008), de maneira a fornecer informações e conhecimento apropriados às decisões. (TYSON, 1998)

Embora Sharp (2009) argumente que a IC só deve ter conexão com níveis de discussão essencialmente estratégicos, ou seja, com os líderes da organização, Fleisher e Bensoussan (2007) apontam que pode haver conexões também com níveis táticos e operacionais. A IC, em nível estratégico, está mais ligada a questões de longo prazo (FLEISHER; BENSOUSSAN, 2007) como um suporte à decisão. (BAARS; KEMPER, 2008)

Ao se considerar a IC como parte do processo de administração estratégica, o conhecimento estratégico gerado por ela (TYSON, 1998), a respeito de oportunidades e ameaças (BOSE, 2008), pode ser usado para auxiliar a organização a determinar quais são suas escolhas. (CHOO, 2003)

Dishman e Calof (2008) identificaram o que seria o ciclo de inteligência, baseado em cinco fases: a) planejamento e direcionamento; b) coleta das informações; c) análise; d) comunicação; e e) feedback. De acordo com diversos autores (TYSON, 1998; DISHMAN; CALOF, 2008; BOSE, 2008), a fase de análise, seguinte à coleta, é aquela que gera maior valor ao trabalho de IC. É nesta fase que o processo da IC extrai significado das informações coletadas e cria conhecimento estratégico voltado à ação (TYSON, 1998; DISHMAN; CALOF, 2008; BOSE, 2008). Para Bose (2008), esse é um dos aspectos que a diferencia de outras atividades assemelhadas.

\subsection{Fundamentos Básicos da Visão Baseada em Recursos (VBR)}

A VBR é uma abordagem dentro da Administração Estratégica que considera a empresa como um conjunto de recursos e capacidades que a diferencia das demais concorrentes na obtenção da vantagem competitiva com retornos superiores. (BARNEY; CLARK, 2007)

Conforme Collis e Montgomery (2008), a abordagem da RBV é baseada na teoria econômica e explica como os recursos de uma empresa podem conduzir o seu desempenho em um ambiente dinâmico e competitivo. Para os autores, essa abordagem combina a análise interna dos fenômenos dentro das empresas com a análise externa do setor.

Para Wernerfelt (1984), as organizações são vistas como um conjunto de recursos e capacidades que não podem ser livremente comprados e vendidos no mercado. Acrescenta esse autor que um aumento na lucratividade das empresas pode ser mais bem explicado por seus recursos do que por sua posição de mercado. (PORTER, 1986) 
Cool, Costa e Dierickx (2002) consideram que a disponibilidade de recursos únicos é condição para a obtenção da vantagem competitiva com retornos acima da média em relação aos concorrentes. Esses autores salientam que os retornos superiores dependem não somente da capacidade deles propiciarem uma vantagem competitiva, mas também do tempo que essa vantagem pode ser sustentada.

Barney (1991) pressupõe a existência de duas condições básicas para os recursos serem fontes de vantagem competitiva sustentável: a) a heterogeneidade, que vem a ser a posse de recursos diferenciados, raros em relação aos concorrentes; e b) a imobilidade dos recursos, que é a dificuldade ou inviabilidade de serem imitados ou transferidos, tornando-os únicos e idiossincráticos.

Foss e Knudsen (2003) corroboram esses pressupostos de Barney (1991), ao afirmarem que a VBR se apoia em duas generalizações empíricas. A primeira diz respeito à heterogeneidade dos recursos como causa das diferenças entre empresas, considerando que a vantagem competitiva está fundamentada não em quaisquer recursos, mas naqueles que levem à criação da maior valor econômico que o criado pelos concorrentes. A segunda generalização diz respeito à estabilidade da heterogeneidade, ou imobilidade dos recursos que sustenta a vantagem competitiva ao longo do tempo.

Nos subitens subsequentes estão apresentados mais especificamente os conceitos de vantagem competitiva e de recursos.

\subsection{Vantagem Competitiva}

Barney (1991) defende que uma empresa tem uma vantagem competitiva quando adota uma estratégia que gera valor com base nos seus recursos únicos e que não tenha sido implementada por outra organização. Essa vantagem será sustentável enquanto nenhuma outra concorrente duplicar os benefícios dessa estratégia. Nessa linha, Peteraf (1993) enfatiza que a sustentabilidade da vantagem competitiva, ao longo do tempo, depende dos recursos serem de difícil imitação.

Vasconcelos e Brito (2004) destacam que a vantagem competitiva sempre estaria associada a um determinado intervalo de tempo, pois não é uma posição que a empresa possui como uma característica fixa.
A empresa poderá estar em uma condição de vantagem competitiva sustentável por um período de tempo, mas a situação pode mudar dependendo das mudanças na empresa, nos concorrentes e no próprio mercado.

Segundo Barney e Clark (2007), a vantagem competitiva é avaliada pelo valor econômico superior que a estratégia da empresa consegue criar em relação às suas rivais. $\mathrm{O}$ valor econômico é constituído pela diferença entre o custo econômico total do produto ou serviço oferecido pela empresa e a percepção do benefício ganho pelo cliente sobre ele. A questão do custo econômico é importante, uma vez que o conceito de vantagem competitiva sustentável tem a ver com a obtenção de ganhos superiores pela organização em relação aos seus concorrentes. (PETERAF; BARNEY, 2003)

Besanko et al. (2006) e Hitt, Ireland e Hoskinsson (2008) definem vantagem competitiva em termos do resultado da empresa no emprego combinado de seus recursos. Quando uma empresa obtém uma taxa maior de lucro do que a taxa média de lucro de outras empresas disputando o mesmo mercado, a empresa possui uma vantagem competitiva nesse mercado. (BESANKO et al., 2006)

A vantagem competitiva, de acordo com Collis e Montgomery (2008), pode ser atribuída a uma empresa que realiza atividades melhor ou com menor custo do que seus concorrentes com os recursos disponíveis. Assim, a obtenção de desempenho superior baseia-se na combinação do desenvolvimento de um conjunto distinto de recursos estratégicos com sua utilização em uma estratégia eficientemente concebida.

\subsection{Recursos}

A seguir serão apresentados os tipos de recursos, os estratégicos: de valor, de raridade, de inimitabilidade e de organização.

\subsubsection{Tipos de Recursos}

Wernerfelt (1984) distingue os recursos entre tangíveis e intangíveis. Barney e Clark (2007) entendem que recursos tangíveis englobam todos os ativos concretos da organização, como fábricas, prédios, máquinas, produtos, localização, entre outros. Quanto aos intangíveis, eles não podem ser materializados e 
estão mais relacionados a elementos como conhecimento, interação entre equipes, reputação corporativa, entre outros.

Os recursos intangíveis, para Hall (1992), são fontes de maiores ganhos, pela dificuldade ou mesmo a impossibilidade de serem imitados ou transferidos. Ou seja, quanto mais difícil de observar, medir e comparar, mais difícil é imitar ou substituir um recurso e, portanto, maior a vantagem competitiva que pode ser extraída desses recursos.

Recursos intangíveis podem ser encontrados de diversas formas nas organizações. Kristandl e Bontis (2007) os observam em áreas relacionadas ao capital intelectual, como a área jurídica, gerencial, processual, entre outros. Hall (1992) faz uma diferenciação entre recursos intangíveis que são ativos ou habilidades. Para ele, recursos intangíveis que podem ser vistos como ativos são marcas, patentes, direitos autorais, identidades visuais registradas, contratos, segredos industriais, reputação e redes de relacionamento. Já os recursos intangiveis considerados como habilidades se resumem a know-how e cultura e são dependentes de pessoas.

Estudo conduzido por Lopez (2003), com base nos conceitos de Hall (1992), mostrou que os recursos intangíveis mais dependentes de pessoas são os que oferecem melhores retornos econômicos em relação aos concorrentes.

\subsubsection{Recursos Estratégicos}

O objetivo deste item é apresentar os atributos dos recursos a serem utilizados na identificação da IC como um possível recurso estratégico, nas próximas seções.

Para Barney e Clark (2007), há quatro atributos básicos para determinar se um recurso possui as características necessárias para ser uma fonte de vantagem competitiva, quais sejam: a) capaz de gerar valor para a organização; b) ser raro; c) difícil de imitar; e d) disponha de uma organização favorável ao seu aproveitamento. Esses atributos compõem o modelo VRIO - Valor, Raridade, Inimitabilidade e Organização, detalhado a seguir.

\subsubsection{Valor}

O atributo do valor diz respeito à condição do recurso gerar valor econômico ao produto ou a redução dos custos econômicos (PETERAF; BARNEY, 2003), que são essenciais para a obtenção da vantagem competitiva.

Collis e Montgomery (2008) destacam que o valor de um recurso deve ser obtido por intermédio de sua comparação com os concorrentes. Assim, uma organização só saberá se seus recursos são valiosos se os comparar com outra organização concorrente.

a) Raridade: a raridade está ligada à heterogeneidade defendida por Peteraf (1993), pois em meio à diversidade de recursos da organização, aqueles escassos é que são capazes de prover vantagem competitiva. Barney e Clark (2007) definem um recurso raro como o que é controlado por uma ou por muito poucas organizações de um mesmo setor. A visão de heterogeneidade de Peteraf (1993) é de que uma diversidade de recursos disponíveis no mercado pode resultar em uma raridade de um recurso que possa trazer ganhos acima da média. (DIERICKX; COOL, 1989)

b) Inimitabilidade: a inimitabilidade tem a ver com os custos (de oportunidade) associados à imitação ou transferência de um determinado recurso por uma organização concorrente (BARNEY, 2011). Esse atributo está relacionado à duração da vantagem competitiva, se episódica ou sustentável. Um fator relacionado à inimitabilidade diz respeito às condições em que o recurso é desenvolvido numa determinada organização ou, nos termos de Barney (1991), a path dependence, ou seja, o desenvolvimento histórico de um determinado recurso que obrigaria o imitador a percorrer os mesmos caminhos. Outros fatores relevantes relacionados à inimitabilidade são a ambiguidade causal e a complexidade social (BARNEY; CLARK, 2007). A ambiguidade causal ocorre quando é muito difícil identificar as variáveis responsáveis pelo sucesso ou fracasso de uma estratégia que poderia ser imitada (DIERICKX; COOL, 1989). A complexidade social está ligada, por exemplo, ao relacionamento interpessoal entre os indivíduos na organização ou entre esses indivíduos e atores externos relevantes, o que também seria de difícil imitação.

c) Organização: as condições existentes na organização para utilização produtiva dos recursos compõem um atributo indispensável para a sua identificação e desenvolvimento visando à 
obtenção e manutenção da vantagem competitiva (BARNEY; CLARK, 2007). Tais condições organizacionais se referem a estruturas formais $e$ informais, sistemas de controle gerencial $e$ políticas de remuneração, enfim processos $e$ políticas que suportam o funcionamento da organização.

O atributo da existência de condições organizacionais é relevante, por exemplo, em um processo de fusão e aquisição em que a organização compradora pode adquirir controle de alguns recursos intangiveis que não dependem de pessoas, como patentes, mas não tem garantia sobre outros que dependem de pessoas, enraizados por meio do conhecimento, know-how, competências e habilidades. (HALL, 1992)

De acordo com Barney e Clark (2007), os recursos valiosos e raros podem constituir fontes de vantagens competitivas. Entretanto, para que a vantagem competitiva seja sustentável é necessário que os recursos não sejam imitáveis por outras empresas, além do que a empresa deve estar organizada para explorar o potencial oferecido por estes recursos.

\section{Procedimentos Metodológicos}

A pesquisa que fundamenta este artigo foi exploratório-descritiva, de natureza qualitativa. Dado que o caráter descritivo é característico da pesquisa qualitativa, buscou-se prover detalhes a respeito do contexto pesquisado (CRESWELL, 2007). Procurou-se captar a visão das pessoas envolvidas nas práticas da IC a partir dos elementos da sua realidade (GODOY, 1995). Além disso, boa parte das pesquisas com a abordagem da VBR tem sido feita com a utilização do método qualitativo. (NOTHNAGEL, 2008)

Nesse sentido, foram realizadas entrevistas em profundidade com profissionais de IC das empresas que participaram da pesquisa, orientadas por um roteiro padrão estruturado com perguntas abertas (AAKER; KUMAR; DAY, 2002). O tratamento e a análise dos dados foram realizados por meio da Análise de Conteúdo. (BARDIN, 2006; FLICK, 2009)

\subsection{Entrevistas}

O roteiro das entrevistas constou de 12 perguntas abertas padronizadas, tendo em vista o objetivo da pesquisa, elaboradas de maneira a manterem a conexão com o Referencial Teórico. Essa prática visou a facilitar a realização das etapas posteriores de tratamento e análise dos dados e a garantir a consistência básica do trabalho. As entrevistas foram gravadas em áudio e posteriormente transcritas e, em seguida, cuidadosamente revisadas para garantir a sua fidelidade.

\subsection{Ambiente da Pesquisa e Coleta dos Dados}

Os entrevistados foram escolhidos intencionalmente de acordo com a prática usual na pesquisa qualitativa (CRESWELL, 2007) e à sua facilidade de acesso. Foram entrevistados seis gestores diretamente responsáveis pela atividade de IC em empresas de grande porte de diferentes negócios, detentores de conhecimentos relevantes para o estudo, entre os meses de agosto e outubro de 2012. O tempo de experiência profissional dos gestores variou entre dois e quinze anos, nessa atividade ou em correlatas. A primeira entrevista serviu como um pré-teste do roteiro, tendo sido aproveitada boa parte das perguntas no ajuste para a versão definitiva. As respostas foram descartadas.

Todas as empresas já tinham a IC institucionalizada na sua estrutura. Fez parte da estratégia da pesquisa não incluir mais de uma empresa do mesmo negócio (concorrentes imediatos), uma vez que a função de IC trata com dados sigilosos e dificultaria o acesso aos entrevistados.

Como as empresas não autorizaram a sua identificação foi mantido o sigilo acertado com os entrevistados, mas o Quadro 3 apresenta uma breve descrição do negócio de cada uma delas e da localização da IC na sua estrutura organizacional. 


\begin{tabular}{|c|c|c|}
\hline EMPRESA & DESCRIÇÃo do NEGóCIO & $\begin{array}{c}\text { LOCALIZAÇÃO DA IC NA } \\
\text { ESTRUTURA }\end{array}$ \\
\hline E1 & $\begin{array}{l}\text { Multinacional do setor de } \\
\text { produtos químicos } \\
\text { industriais: aromas e } \\
\text { fragrâncias para produtores } \\
\text { dos setores cosméticos e } \\
\text { alimentícios. }\end{array}$ & $\begin{array}{l}\text { Na área de marketing, } \\
\text { voltada a estratégia de } \\
\text { produtos e vendas } \\
\text { regionais. }\end{array}$ \\
\hline E2 & $\begin{array}{l}\text { Multinacional de soluções } \\
\text { de projeto de engenharia } \\
\text { para o setor de energia: } \\
\text { projetos para construção de } \\
\text { usinas de energia, } \\
\text { especialmente hidrelétricas. }\end{array}$ & $\begin{array}{l}\text { Na área de marketing } \\
\text { estratégico, como suporte } \\
\text { ao planejamento } \\
\text { estratégico regional. }\end{array}$ \\
\hline E3 & $\begin{array}{l}\text { Empresa nacional, } \\
\text { fabricante de produtos para } \\
\text { a saúde animal: vacinas de } \\
\text { uso veterinário. }\end{array}$ & $\begin{array}{l}\text { Com organização própria } \\
\text { (diretoria), voltada ao } \\
\text { planejamento estratégico } \\
\text { corporativo, às estratégias } \\
\text { de produtos e vendas. }\end{array}$ \\
\hline E4 & $\begin{array}{l}\text { Empresa multinacional, } \\
\text { provedora de produtos e } \\
\text { serviços para infraestrutura } \\
\text { de telecomunicações: } \\
\text { equipamentos para redes } \\
\text { de telecomunicações, } \\
\text { públicas e privadas, além } \\
\text { de serviços para a sua } \\
\text { operação. }\end{array}$ & $\begin{array}{l}\text { Na área de estratégia e } \\
\text { marketing regional, } \\
\text { envolvendo } \\
\text { planejamento estratégico } \\
\text { corporativo regional, } \\
\text { vendas de produtos e } \\
\text { serviços. }\end{array}$ \\
\hline E5 & $\begin{array}{l}\text { Empresa multinacional de } \\
\text { commodities: derivados de } \\
\text { minérios, em especial o } \\
\text { alumínio em diversas } \\
\text { formas. }\end{array}$ & $\begin{array}{l}\text { Na área de compras e } \\
\text { estratégias de } \\
\text { suprimentos. }\end{array}$ \\
\hline E6 & $\begin{array}{l}\text { Empresa multinacional do } \\
\text { setor automobilístico: } \\
\text { automóveis, projetados } \\
\text { fora do país, tendo a } \\
\text { montagem final de alguns } \\
\text { modelos instalada no } \\
\text { Brasil. }\end{array}$ & $\begin{array}{l}\text { Na área de planejamento } \\
\text { estratégico regional, } \\
\text { envolvida com estratégias } \\
\text { de marketing e vendas } \\
\text { regionais. }\end{array}$ \\
\hline
\end{tabular}

Quadro 3: Descrição das empresas da pesquisa por ordem das entrevistas

Fonte: Elaborado pelos autores deste artigo

\subsection{Tratamento dos Dados}

Os dados da pesquisa foram tratados por meio da Análise de Conteúdo, adotadas as recomendações de Flick (2009), segundo as quais o tratamento de dados qualitativos compreende a codificação e a categorização, e de Bardin (2006), para quem essa técnica envolve as seguintes etapas: a) pré-análise; b) exploração do material; e c) tratamento dos resultados e interpretação.
A pré-análise correspondeu à organização das entrevistas transcritas de maneira a ajustar as respostas às perguntas na ordem em que foram estruturadas no roteiro, para facilitar o seu agrupamento por significados. Isso se fez necessário por que algumas respostas foram dadas ou complementadas em outras perguntas. Com isso, foi criada uma moldura de codificação (COLLIS; HUSSEY, 2005) para se verificar a consistência entre os diversos depoimentos. O roteiro das entrevistas constituiu a regra básica de codificação que orientou a transformação das falas transcritas em unidades de registro (BARDIN, 2006), ou unidades de código, conforme Collis e Hussey (2005).

A etapa de exploração do material consistiu em destacar nas transcrições das entrevistas as unidades de registro, ou seja, as palavras-chaves, expressões e frases mais aderentes ao significado básico de cada pergunta. Em seguida, essas unidades foram transpostas para uma planilha contendo as perguntas na primeira coluna e nas demais colunas, no sentido da esquerda para a direita, as unidades correspondentes a cada entrevistado. Esse procedimento correspondeu à preparação para a categorização (BARDIN, 2006) que decorreu da codificação. (FLICK, 2009)

O tratamento dos dados foi iniciado com base nas unidades de registro, distribuídas na planilha. Foram feitas várias leituras horizontais, elegendo-se uma pergunta de cada vez e confrontando as unidades de registro de cada respondente para se elaborar os temas mais relevantes, por meio de sínteses. Ao final desse procedimento obteve-se uma relação dos temas mais aderentes aos objetivos específicos da pesquisa.

O procedimento seguinte consistiu na elaboração das categorias para a análise do material que, segundo Bardin (2006), tem como finalidade fornecer, por meio de condensações, uma representação dos dados brutos. Para esse procedimento foram obedecidos os critérios para uma categorização produtiva (BARDIN, 2006), quais sejam: a) exclusão mútua, em que uma unidade de registro só pode ser associada a um código; b) homogeneidade; c) objetividade e fidelidade; e d) produtividade, que possibilita novos insights.

O Quadro 4 apresenta as categorias que resultaram do tratamento dos dados, em conexão com o objetivo do artigo, e que estruturam a análise dos resultados na próxima seção. 


\begin{tabular}{|c|c|}
\hline ObJETIVO do ARTigo & Categorias \\
\hline \multirow{2}{*}{$\begin{array}{l}{[\ldots] \text { inserção na administração }} \\
\text { estratégica da organização [...] }\end{array}$} & $\begin{array}{l}\text { Integradora de informações } \\
\text { e conhecimento. }\end{array}$ \\
\hline & $\begin{array}{l}\text { Facilitadora de decisões } \\
\text { estratégicas. }\end{array}$ \\
\hline \multirow{3}{*}{$\begin{array}{l}{[\ldots] \text { identificação dos }} \\
\text { atributos a ela inerentes [...] }\end{array}$} & $\begin{array}{l}\text { Geradora indireta de } \\
\text { valor econômico. }\end{array}$ \\
\hline & $\begin{array}{l}\text { Dependente de relacionamentos } \\
\text { interpessoais e do tempo } \\
\text { de desenvolvimento. }\end{array}$ \\
\hline & $\begin{array}{l}\text { Diversidade de especialização } \\
\text { e posicionamento na estrutura }\end{array}$ \\
\hline
\end{tabular}

Quadro 4: Categorias resultantes da análise dos dados Fonte: Elaborado pelos autores deste artigo

\section{ANÁLISE E INTERPRETAÇÃo dos Depoimentos}

Esta seção apresenta a interpretação dos depoimentos dos entrevistados conectada com o referencial teórico. Conforme mencionado anteriormente, os entrevistados estão identificados por intermédio da nomenclatura estabelecida no Quadro 3, com o objetivo de assegurar a confidencialidade dos depoimentos. As análises estão apresentadas na mesma ordem sequencial das entrevistas, que é a mesma das empresas apresentadas no referido quadro.

\subsection{Integradora de Informações e Conhecimento}

Um dos aspectos mais relevantes identificados no primeiro momento foi a maneira como a IC é percebida dentro da empresa, mais especificamente no nível da administração estratégica.

Os entrevistados expuseram que a IC atua como uma integradora de informações e conhecimentos dispersos nos diversos departamentos da empresa (RODRIGUES; RICCARDI, 2007). Para realizar essa integração, a área de IC busca informações e conhecimento disponíveis tanto internamente como externamente à empresa e os entrega a algumas poucas pessoas nas empresas.

A IC é uma atividade de adoção recente nas empresas dos entrevistados, tendo em média cinco anos de existência. Além disso, em alguns casos, observou-se pouca clareza a respeito da relação entre a IC e as práticas de gestão do conhecimento. Quanto a essa última não estava institucionalizada em nenhuma das empresas, apesar de ser clara a ligação entre a IC e o conhecimento existente dentro da organização (BOLLINGER; SMITH, 2001; CHOO, 2003; MAKADOK; BARNEY, 2001). Os depoimentos, a seguir, ilustram essa situação:

[...] nós usamos metodologias de IC para fazer gestão do conhecimento. (gestor da E1)

[...] um pouco de gestão de conhecimento, mas não é nada formalizado. (gestor da E6)

De acordo com os entrevistados, não raramente a IC é demandada a realizar trabalhos associada com outras funções como, planejamento estratégico, marketing, vendas, entre outras. Essa associação, contudo, seria caracterizada de melhor forma como uma relação "fornecedor - cliente", seja no caso do planejamento estratégico em que a IC é a fornecedora, seja em outros casos em que a IC se vale de informações sobre o ambiente externo que estão disponíveis nas áreas de vendas e compras, conforme ilustram os depoimentos:

[...] a gente faz aquelas análises básicas chamadas de STEEP, que é social, tecnológica, econômica, ecológica, política, para identificar quais são as mudanças que estão acontecendo [...]. (gestor da E1)

[...] é feita uma avaliação dos principais competidores [...] com um acompanhamento de grandes movimentos. [...] e também do que está acontecendo com determinado segmento. (gestor da E2)

O planejamento estratégico [...] começou a fazer inteligência competitiva com todo o ferramental de suporte às decisões. É o ambiente de inteligência competitiva que detecta as oportunidades. (gestor da E3)

A área de estratégia e marketing trabalha de uma forma que a gente chama de outsiding, ou seja, olhando as perspectivas de fora da empresa, do mercado, para dentro. Há um fórum de discussão interna [...]. (gestor da E4)

[...] pessoas em todo o mundo colocam alguns inputs, algumas notícias, algumas informações que percebem do mercado. A partir desse agrupamento de informações, a área (IC) consegue construir algumas hipóteses [...]. (gestor da E5) 


\subsection{Facilitadora de Decisões Estratégicas}

Um dos mais relevantes benefícios percebidos pelos entrevistados de se ter a IC nas empresas é a facilitação às decisões estratégicas (BAARS; KEMPER, 2008; DISHMAN; CALOF, 2008; HITT; IRELAND; HOSKISSON, 2008), nos seguintes aspectos: 1) benefícios para os níveis estratégicos e operacionais; 2) fácil acesso a informações e conhecimento; e 3) identificação de riscos.

Com relação aos benefícios, a área de IC atende desde o presidente da empresa até pessoas de nível gerencial e operacional, facilitando o acesso à informações e ao conhecimento disponíveis internamente (FLEISHER; BENSOUSSAN, 2007; BOSE, 2008; SHARP, 2009), conforme o depoimento a seguir:

[...] tem gente que atua no campo recebendo produtos (da IC), que é cliente interno nosso $e$ tem gente que é o próprio diretor que recebe nossos produtos [...] (gestor da E3)

Quanto à acessibilidade a informações e conhecimento (CHOO, 2003; MAKADOK; BARNEY, 2001), a interação entre fornecedor e clientes internos acontece tanto de forma proativa, por parte dos responsáveis pela IC, quanto por demandas específicas, conforme ilustram os depoimentos a seguir:

[...] criar insights [...] para onde está indo o mercado $e[\ldots]$ principalmente dados $e$ fatos que comprovem alguns desses insights [...] (gestor da E4)

[...] agilidade, flexibilidade, sinergia na comunicação e tomadas de decisões mais rápidas [...] (gestor da E6)

O terceiro aspecto é o fato de a IC ser entendida como uma identificadora de riscos (CASTRO; ABREU, 2007; DISHMAN; CALOF, 2008; SHARP, 2009). Segundo os entrevistados, mais do que as oportunidades identificadas no ambiente externo, os riscos percebidos pela IC é que são de fato úteis à administração estratégica da empresa. (TYSON, 1998; CHOO, 2003; DISHMAN; CALOF, 2008; SHARP, 2009)

Ficou claro que a IC, sozinha, não é impreterível para o processo decisório. No entanto, ela é utilizada pelos gestores da alta administração que tomam essas decisões para embasamento ou refutação das escolhas realizadas (CHOO, 2003), apesar das dificuldades políticas, em alguns casos. Portanto, é possível afirmar que uma contribuição relevante da IC para as decisões estratégicas das empresas da pesquisa acontece por intermédio da identificação de riscos.

\subsection{Geradora Indireta de Valor Econômico}

Houve unanimidade de percepção entre os entrevistados com relação ao efeito indireto da IC na geração de valor econômico aos clientes das empresas. Partindo do conceito de que a vantagem competitiva está intrinsecamente ligada à geração de valor econômico (PETERAF; BARNEY, 2003), sendo um dos seus aspectos relevantes o valor percebido pelo cliente quanto aos produtos ou serviços, os entrevistados entendem que a IC possui uma ligação apenas indireta com a geração desse valor, conforme os depoimentos a seguir:

[...] a IC ajuda a entender qual é o valor percebido para aquele cliente. [...] para você oferecer uma solução diferente de um cliente para outro. (gestor da E2

[...] tem que entender a necessidade do cliente para mudar os produtos que ele demanda [...] (gestor da E3)

[...] não diretamente, a gente não participa do processo de formulação de produtos [...] é um papel informativo. (gestor da E4)

\subsection{Dependente de Relacionamentos Interpessoais e do Tempo de Desenvolvimento}

Por ser uma atividade basicamente de "prestação de serviço" foi identificada uma óbvia dependência do relacionamento entre pessoas para a atuação eficiente e eficaz da IC. Essa dependência de pessoas é uma das características dos recursos estratégicos (HALL, 1992; BARNEY; CLARK, 2007; LOPEZ, 2003), decorrente do seu enraizamento na empresa por meio da interação entre equipes, desenvolvimento $e$ aplicação do conhecimento, desenvolvimento de competências $e$ habilidades, entre outros. Nesse caso, identificou-se como relevante a complexidade social (BARNEY; CLARK, 2007) desenvolvida entre fornecedores e clientes internos, bem como com pessoas do alto nível hierárquico, na forma de um sistema social (RODRI- 
GUES; RICCARDI, 2007; CHOO, 2003), ilustrado nos depoimentos:

\footnotetext{
Se a área (IC) mantém um bom relacionamento com toda a empresa, consegue mais acesso à informação, à capacidade analítica, e consegue mais apoio de executar aquelas recomendações que foram feitas (Gestor da E1)

A área da IC procura estar bem integrada com as outras áreas, principalmente as que são fontes de informação primária [...] (gestor da E2)

O responsável pela área de IC cria relacionamentos [...] para garantir a cooperação [...] (gestor da E3)

[...] a gente procura internamente algum contato, alguma pessoa que trabalha em uma área técnica e tenha o conhecimento que pode direcionar a nossa pesquisa $e$ a nossa estratégia [...] (gestor da E5)
}

Identificou-se que o tempo de desenvolvimento da atividade de IC para poder oferecer produtos de valor para a empresa foi de dois anos, em média. Questionados se esse tempo poderia ser encurtado com a incorporação de novos recursos na realização da atividade, os entrevistados foram reticentes e céticos, corroborando a posição de Dierickx e Cool (1989) de que essa situação configuraria uma "deseconomia" de compressão de tempo. Os depoimentos a seguir ilustram esta alternativa:

[...] um dos processos mais importantes pelo qual você precisa passar é o de convencimento interno, mas isso requer tempo [...]. (gestor da E1)

Há um processo inevitável, o do amadurecimento da própria área em termos de aprender como interagir na organização [...] (gestor da E2)

\subsection{Diversidade de Especialização e Posicionamento na Estrutura}

Constatou-se que o que diferencia efetivamente a atividade de IC de uma empresa para outra é a maneira como ela é abrigada e exercida em cada uma delas. (BARNEY; CLARK, 2007)

Foram identificados dois elementos determinantes na diversidade de configurações: 1) o nível de especialização da IC; e 2) o seu posicionamento na estrutura organizacional das empresas.
Com relação à especialização, o perfil das pessoas que atuam nessa atividade e a sua dedicação são os fatores que fazem com que ela seja única em uma determinada empresa em comparação a outras. Para os entrevistados, a IC especializada é bem mais focada na sua atuação, conforme os depoimentos a seguir:

Uma boa parte das empresas que afirmam ter uma área de inteligência, na realidade tem uma área de pesquisa de mercado. (gestor da E1)

Essa tratativa que a gente dá, de inteligência competitiva pura, é só da nossa empresa. Muitos [...] concorrentes sabem que nós temos isso e até gostariam de ter. Mas eles não conseguem [...]. (gestor da E3)

Com relação ao posicionamento da IC na estrutura organizacional, cada empresa da pesquisa a mantém em locais diferentes na hierarquia, tendo em vista a sua atuação com negócios diferentes que exigem estruturas diferentes. Consequentemente, o acesso que as pessoas da IC têm aos decisores estratégicos também varia de acordo com a posição desta na estrutura organizacional. O depoimento a seguir ilustra esse aspecto:

[...] cada empresa trabalha de um jeito, foco em marketing estratégico, planejamento estratégico, inteligência de mercado. (gestor da E6)

\section{Considerações Finais}

Retomando o objetivo básico deste artigo, o de examinar a perspectiva da IC se constituir em uma fonte de vantagem competitiva, é possível afirmar que esta não pode ser considerada como tal, de acordo com os conceitos da VBR, ao menos em relação às empresas que participaram da pesquisa.

Um dos aspectos específicos destacados, qual seja, a inserção da IC na administração estratégica, revelou que esta não atua de maneira integrada à gestão do conhecimento que, por seu lado, não estava institucionalizada nas empresas da pesquisa. Aparentemente, os produtos da IC atendem às necessidades dos clientes internos de maneira mais pontual e célere. Outra revelação é a facilidade de integração da IC com outras atividades de inteligência mais específicas como marketing e operações. É também relevante 
acrescentar que a análise das informações de natureza estratégica e operacional tem sido um apoio efetivo ao processo decisório, especialmente como uma identificadora de riscos que é considerada como o diferenciador da IC em relação às outras inteligências.

Com relação aos atributos que indicariam a IC como um recurso estratégico passível de geração de vantagem competitiva, ficou claro que pelos critérios do modelo VRIO praticamente nenhum deles foi atendido. Isso foi revelado pelas categorias de análise resultantes do tratamento dos depoimentos.

Pela categoria referente à geração indireta de valor econômico, fica claro que a IC não é suficientemente robusta para gerar valor percebido pelos clientes aos produtos e serviços das empresas da pesquisa, mesmo em se tratando de ramos de negócios bastante distintos. Em nenhum momento essa condição foi admitida.

A categoria, dependência de relacionamentos interpessoais e do tempo de desenvolvimento, é a que revelou a atividade de IC mais próxima a um recurso estratégico por conter os atributos de raridade e de imitação onerosa. Quanto à raridade, esta se apoia basicamente na característica da dependência de relacionamentos interpessoais, pois a IC é essencialmente uma prestadora de serviços. Assim, a relação cliente interno - equipe de IC de cada empresa poderia ser considerada como um ativo intangível raro, dependente de pessoas, apesar de não ter havido a comparação com os concorrentes de nenhuma delas. De fato, o relacionamento interpessoal foi manifestado de maneira muito expressiva, não deixando dúvidas quanto à sua relevância como um atributo potencialmente diferenciador da IC entre empresas concorrentes.

A imitação onerosa tem muito a ver com a característica do tempo gasto para o desenvolvimento da atividade de IC, do que em relação à path dependence ou à ambiguidade causal. Essa dificuldade, contudo, poderia ser contornada com a sua substituição por outra atividade de inteligência, dada a facilidade com que a IC se articula ou se integra com elas. A alternativa seria a contratação de profissionais experientes de outras empresas, tendo em vista que a "tecnologia" do processo da IC é conhecida e depende pouco do tipo de negócio em que se realiza. Alie-se a isso, o fato de haver programas de treinamento e formação de profissionais dessa atividade em âmbito internacional e nacional, conforme referidos na introdução deste artigo, o que ajuda a disponibilizar mais pessoas capacitadas a atuar na atividade de IC.

A última categoria, diversidade de especialização e posicionamento na estrutura, caracterizou o quarto atributo do modelo VRIO, o da organização que suporta e privilegia os recursos estratégicos. A diversidade de especialização tem a ver com a cultura da empresa que valoriza, umas mais outras menos, o relacionamento interpessoal no sentido horizontal e vertical, bem como a atuação da IC como uma atividade pura ou sobreposta a outras atividades assemelhadas. Quanto ao posicionamento na estrutura este é único de cada empresa, por conta da busca pela vantagem competitiva. Em outras palavras, cada empresa opera de uma forma específica, cada empresa assume uma estrutura organizacional específica, $e$ isso faz com que o posicionamento da IC e sua efetividade também sejam singulares em cada empresa.

Em resumo, a pesquisa revelou que mesmo a IC não estando intimamente envolvida na geração de valor dos produtos ou serviços das empresas, a sua contribuição é relevante para as decisões dos executivos, quando institucionalizada na sua estrutura. Além disso, trata-se de uma atividade que pode assumir a condição de raridade e de imitação onerosa, posicionada na parte estratégica da estrutura, o que lhe confere a condição de coadjuvante na geração da vantagem competitiva.

Entre as contribuições pretendidas por este artigo, uma delas é a de tornar mais claro o papel da IC, sua configuração, inserção e contribuição à administração estratégica, por ser uma atividade em expansão e institucionalizada mais recentemente, bem como a sua relação com as demais inteligências, ainda incipiente na literatura.

A outra é a ampliação do conhecimento sobre a adequação e eficiência dos conceitos da VBR para tratar as questóes de natureza estratégica levantadas na introdução. Essa abordagem permitiu se tratar com objetividade, desde a elaboração do instrumento de coleta dos dados até as análises, tendo em vista a natureza qualitativa da pesquisa. A adoção do modelo VRIO facilitou aos entrevistados a caracterização dos atributos da IC o que resultou em depoimentos produtivos.

Por fim, é oportuno destacar que algumas limitações ocorreram no desenvolvimento da pesquisa, entre 
elas o fato de terem sido entrevistados apenas pessoas envolvidas na atividade de IC, sem um contraponto em relação aos seus clientes internos, o que poderia ter trazido uma compreensão mais ampla sobre os seus resultados. Essa é a sugestão para um próximo estudo.

\section{REFERÊNCIAS}

AAKER, D. A.; KUMAR, V.; DAY, G. S. Pesquisa de marketing. São Paulo: Atlas, 2001.

\section{ABREU, Paulo G. F. de. Processo decisório e monitoramento do ambiente competitivo: uma contribuição à luz da abordagem contingencialista e da inteligência competitiva. Belo Horizonte, MG. Dissertação de mestrado, Pontifícia Universidade Católica de Minas Gerais, Fundação Dom Cabral, 2006.}

ACADEMY of Competitive Intelligence. Corporate Alumni, Cambridge, 2010. Disponível em: <http://www. academyci.com/About/alumni.html > . Acesso em: 28 ago. 2011.

BAARS, H.; KEMPER, H. G. Management Support with Structured and Unstructured Data - an Integrated Business Intelligence Framework. Information Systems Management, Abingdon, v. 25, p. 132-145, 2008.

BARDIN, L. Análise de conteúdo. Lisboa: Edições 70, 2006.

BARNEY, J. B. Strategic factor markets: expectations, luck, and business strategy. Management Science, USA, v. 32, n. 10, Outubro, 1986.

BARNEY, J. Firm resources and sustained competitive advantage. Journal of Management, Thousand Oaks, v. 17, n. 1, p. 99-120, Mar., 1991.

BARNEY, J. B.; CLARK, D. N. Resource-Based theory: creating and sustaining competitive advantage. Oxford University Press: New York, 2007.

BARNEY, J. B. Gaining and sustaining competitive advantage. 4. ed. Boston: Prentice Hall, 2011.

BESANKO, D. et al. A economia da estratégia. 3. ed. Porto Alegre: Bookman, 2006.
BOLLINGER, A. S; SMITH, R. D. Managing organizational knowledge as a strategic asset. Journal of Knowledge Management, USA, v. 5, n. 1, p. 8-23, 2001.

BOSE, R. Competitive intelligence process and tools for intelligence analysis. Industry Management \& Data Systems, USA, v. 108, n. 4, p. 510-528, 2008.

CALOF, J. L.; WRIGHT, S. Competitive intelligence - a practitioner, academic and inter-disciplinary perspective. European Journal of Marketing, USA, v. 42, n. 7/8, p. 717-730, 2008.

CASTRO, J. M.; ABREU, P. Estaremos cegos pelo ciclo da inteligência tradicional? Uma releitura a partir das abordagens de monitoramento ambiental. Ciência da Informação, v. 36, n. 1, p. 7-19, jan.-abr., 2007.

CHOO, C. W. A organização do conhecimento. 1. ed. São Paulo: SENAC, 2003.

COLLIS, D. J.; MONTGOMERY, C. A. Competing on resources. Harvard Business Review, USA, v. 86, n. 7/8, p. 140, Jul.-Aug., 2008.

COLLIS, J.; HUSSEY, R. Pesquisa em administração. 2. ed. Porto Alegre: Bookman, 2005.

COOL, K.; COSTA, L. A.; DIERICKX, I. Constructing competitive advantage. In: PETTIGREW, Andrew; THOMAS Howard; WHITTINGTON, Richard. Handbook of Strategy and Management. London: Sage, 2002.

CRESWELL, J. W. Projeto de pesquisa. 2. ed. Porto Alegre: Artmed, 2007.

DIERICKX, I.; COOL, K. Asset stock accumulation and sustainability of competitive advantage. Management Science, USA, v. 35, n. 12, p. 1.505-1.514, 1989.

DISHMAN, P. L.; CALOF, J. L. Competitive intelligence: a multiphasic precedent to marketing strategy. European Journal of Marketing, USA, v. 42, n. 7/8, p. 766-785, 2008.

FLEISHER, C. S.; BENSOUSSAN, B. E. Business and competitive Analysis: an effective application of new and classic methods. 1. ed. New Jersey: Financial Times Press, 2007. 
FLICK, U. Desenho da pesquisa qualitativa. Porto Alegre: Bookman, 2009.

FOSS, N.; KNUDSEN, T. The resource-based tangle: towards a sustainable explanation of competitive advantage. Managerial and Decision Economics, USA, v. 24, n. 4, p. 291-307, 2003.

\section{GLOBAL Intelligence Alliance. Global Market}

Intelligence Survey 2009. Helsinki, Outubro, 2009.

Disponível em: <http://www.globalintelligence.com/ insights-analysis/white-papers/global-market-intelligencesurvey-2009>. Acesso em: 6 maio 2011.

GODOY, A. S. A pesquisa qualitativa e sua utilização em administração de empresas. Revista de Administração de Empresas, São Paulo, v. 35, n. 4, p. 65-71. jul.-ago., 1995.

HALL, R. The strategic analysis of intangible resources. Strategic Management Journal, USA, v. 13, n. 2, p. 135-144, fev. 1992.

HARRISON, J. S. Administração estratégica de recursos e relacionamentos. Porto Alegre: Bookman, 2005.

HITT, M. A.; IRELAND, D.; HOSKISSON, R. E. Administração estratégica. São Paulo: Cengage, 2008.

JOHNSON, G.; SCHOLES, K.; WHITTINGTON, R. Explorando a estratégia corporativa 7. ed. Porto Alegre: Bookman, 2007.

KRISTANDL, G.; BONTIS, N. Constructing a definition for intangibles using the resource based view of the firm. Management Decision, USA, v. 45, n. 9, p. 1.510$1.524,2007$.

LOPEZ, Vicente A. Intangible resources as drivers of performance: evidences from a spanish study of manufacturing firms. Irish Journal of Management, USA, v. 24, n.2, 2003.

MAKADOK, R.; BARNEY, J. B. Strategic Factor Market Intelligence: an Application of Information Economics to Strategy Formulation and Competitor Intelligence.

Management Science, USA, v. 47, n. 12, December, 2001
NOTHNAGEL, Katja. Empirical research within resource-based view: a meta-analysis of the central propositions. Wiesbaden: Gabler, 2008.

OLIVEIRA, P. H.; GONÇALVES, C. A.; PAUlA, E. A. M. de. A visão baseada em recursos da inteligência competitiva. Revista de Ciências da Administração, Florianópolis, v. 15, n. 35, p. 141-151, abr. 2013.

PETERAF, M. A. The cornerstones of competitive advantage: a resource-based view. Strategic Management Journal, USA, v. 14, n. 3, p. 179-191, 1993.

PETERAF, M. A.; BARNEY, J. B. Unraveling the ResourceBased Tangle. Managerial and Decision Economics, USA, v. 24, n. 4, p. 309-323, Jun./Jul., 2003.

PORTER, M. E. Estratégia competitiva. Rio de Janeiro: Elsevier, 1986.

PRESCOTT, J. E. The evolution of Competitive Intelligence: designing a process for action. Journal of the Association of Proposal Management Professionals, USA, p. 37-52, Spr., 1999.

RAJANIEMI, K. Internet-based scanning of the competitive environment. Benchmarking: An International Journal, USA, v. 14, n. 4, p. 465-481, 2007.

RODRIGUES, L. C.; RICCARDI, R. Inteligência Competitiva nos negócios e organizações. Maringá: Unicorpore, 2007.

SHARP, S. Competitive intelligence advantage. Hoboken: Wiley, 2009.

TYSON, K. W. M. The complete guide to competitive Intelligence: gathering, analyzing, and using competitive intelligence. Chicago: Kirk Tyson International, 1998.

VASCONCELOS, F. C.; BRITO, L. A. L. Vantagem competitiva: o construto e a métrica. Revista de Administração de Empresas, São Paulo, v. 44, n. 2, abr.-jun. 2004.

WERNERFELT, B. A resource-based view of the firm. Strategic Management Journal, USA, v. 5, n. 2, p. 171-180, Apr.-Jun., 1984 